\title{
Review Article \\ Review of the Socket Design and Interface Pressure Measurement for Transtibial Prosthesis
}

\author{
Gh. Pirouzi, N. A. Abu Osman, A. Eshraghi, S. Ali, H. Gholizadeh, and W.A.B. Wan Abas \\ Department of Biomedical Engineering, Faculty of Engineering, University of Malaya, 50603 Kuala Lumpur, Malaysia
}

Correspondence should be addressed to Gh. Pirouzi; gh.pirouzi@gmail.com

Received 3 March 2014; Revised 21 July 2014; Accepted 24 July 2014; Published 13 August 2014

Academic Editor: Bayram Unver

Copyright (C) 2014 Gh. Pirouzi et al. This is an open access article distributed under the Creative Commons Attribution License, which permits unrestricted use, distribution, and reproduction in any medium, provided the original work is properly cited.

\begin{abstract}
Socket is an important part of every prosthetic limb as an interface between the residual limb and prosthetic components. Biomechanics of socket-residual limb interface, especially the pressure and force distribution, have effect on patient satisfaction and function. This paper aimed to review and evaluate studies conducted in the last decades on the design of socket, in-socket interface pressure measurement, and socket biomechanics. Literature was searched to find related keywords with transtibial amputation, socket-residual limb interface, socket measurement, socket design, modeling, computational modeling, and suspension system. In accordance with the selection criteria, 19 articles were selected for further analysis. It was revealed that pressure and stress have been studied in the last decaeds, but quantitative evaluations remain inapplicable in clinical settings. This study also illustrates prevailing systems, which may facilitate improvements in socket design for improved quality of life for individuals ambulating with transtibial prosthesis. It is hoped that the review will better facilitate the understanding and determine the clinical relevance of quantitative evaluations.
\end{abstract}

\section{Introduction}

Amputation constantly remains a cause of concern for individuals, their families, and society. Incidence of lower limb amputation has increased over the years [1-3]. Amputations, particularly of the lower limb, are increasing in developed countries [4]. Traffic accidents, particularly motorcycle accidents [3] and diabetes, are two major causes [5]. Advanced technologies and environmental, social, and economic factors have led to considerable improvements in prostheses. Prosthetic satisfaction is a subjective notion [6]. Prosthetists consider biomechanical parameters, but people with lower limb amputation remain dissatisfied with prostheses $[7,8]$. The prime objective for any prosthesis is to provide function in a comfortable manner, but comfort is mainly subjective and difficult to standardize $[9,10]$. Comfort primarily involves the pressures between the socket and residual limb. The socket fit, type of prosthetic suspension, and alignment of the prosthesis can alter pressures on the residual limb [11-14].

Essential parts of any prosthesis are socket and suspension mechanism [15]. These parts provide the connection between the residual limb and device. Biomechanical knowledge of the mutual behavior of residual limb, socket, and attachment leads to the improvement of prosthesis functions [16]. Improving the function and comfort will bring satisfaction to patients [17]. After several years of using artificial joint-corset below-knee limb, the patellar tendon bearing (PTB) socket became popular around 1957 [18]. The PTB design demonstrated the concept of concentrated weight bearing. The PTB worked well for approximately $90 \%$ of amputees [19]. The concentration of force caused stretch on skin, which is one of the consequences of injury of residual limb. The PTB prosthesis does not completely solve problems encountered in certain conditions such as, short residual limbs.

Two suspension less below-knee prostheses were introduced that seem to offer certain adv antages over the PTB prosthesis. Both methods include encapsulation of the residual limb with more intimate connection that eliminate the need for any further accessories, such as belt above the knee. A method was developed by Kuhn in the Research Institute Muenster, Germany, called Kondylen-Bein-Munster (KBM). The method provides high enclosure of the femur and the exposure of the patella. Another method, developed 
by Guy Taft, introduced in 1968, provided full enclosure of the patella, medial and lateral femoral condyles, called the patellar-tendon-supracondylar (PTS) [20]. Later in 1993, the total surface bearing (TSB) prosthetic socket, ICEROSS, was suggested by Kristinsson. ICEROSS distributes weight on the whole socket surface [21]. Usual prosthetic sockets are a combination of PTB and TSB. However, the popularity of this method paved the way for the innovation of silicon suction socket (3S) [22], which emphasizes the mechanical features of the material. The emergence of high-precision instruments and application of computers led to a new perspective in the socket-residual limb interface. From 1986 to 1987, Steege et al. [23] took research initiatives in this respect. In the latest research, a method was introduced by Sewell at al., which enabled the prosthetist to analyze the pressure distribution of prosthetic socket by inverse problem analysis approach [24].

Numerous questionnaires have been developed as means of evaluating satisfaction with prosthesis and orthosis [2528]. The Prosthetic Evaluation Questionnaire was introduced to assess satisfaction and problems among users of prosthetic devices. Dillingham et al. [7] conducted a survey and noticed that most of the participants $(n=146)$ were not satisfied with their prostheses due to skin problems and pain. Another study [29] also revealed dissatisfaction with prostheses. Moreover, more than $70 \%$ of participants in a study were more satisfied with the pin/lock suspension system than the Pelite liner [30]. On the contrary, in a prospective study, [30] the majority preferred the Pelite liner. Van de Weg and Van der Windt [31] carried out a research on effect of three transtibial systems on satisfaction and found no significant difference. The objective of this study was to summarize the literature addressing prosthetic biomechanics, socket/residual limb interface, socket fit, pressure distribution, shear force, and their effects on user satisfaction.

\section{Methodology}

2.1. Search. EBSCO, Emerald, ProQuest, PubMed, and Web of Science were searched to find related literature from 1980 to 2013. A total of 421 research papers were found. The following keywords, their variations, and combinations were used for the search: prosthesis, lower limb, amputation, transtibial, below knee, socket, pressure, modeling, suspension, and interface.

2.2. Criteria. English peer-reviewed papers that addressed socket fit and design, computational modeling, and simulation were selected, which mainly focused on pressure distribution, shear force, and friction.

\section{Results}

A total of 421 research papers were found. The titles of each individual study were assessed. Several articles were excluded as being conducted on dental prosthetics, upper limb prosthetics, and implants, or were common between the databases. After refinement, 75 related papers remained. The abstracts of each individual study were assessed, from which 19 papers were selected for the final review.

\subsection{Use of Finite Element Methods (FEM) for Socket Pressure} Measurement. For years, researchers have used finite element methods to study pressure and stress measurement. The foundations of material and fluid physics, such as hydrostatics and Pascal's law, provide a suitable framework for understanding the residual limb and socket behavior [32]. Another issue is whether mere high pressure causes damage to the tissue [33] or size and intervals (high-frequency events, HFE) are also important. Geometric changes in the muscles and materials are deemed important factors. Findings, such as skin damage caused by "a loading cycle (22-118 times) of 4$23 \mathrm{kPa}$ with a friction coefficient of 0.5 " [34], can support this notion because endurance threshold, peak point, and onset of pain are subjective and vary from one person to another. Remarkable ethnic differences also exist in terms of genetics, race, muscle intensity, and skin endurance, thereby lowering the credibility of such experiment results. Such comparisons are ongoing, and the capability of sensors is further enhanced by technological advances, such as the emergence of chips and ultrasensitive fibers [35]. Aside from sensors, computerized modeling has been also considered since 1996.

Similar to an artificial leg, the residual limb is a complicated system with mechanical and biomechanical behaviors. Parameters, such as force distribution, friction, and tension on residual limb against the socket have been investigated through FEM [36]. Tomographic images have also been used to improve 3D FEM modeling. For instance, liner stiffness and its impact on residual limb-socket friction have been evaluated with the solid model constructed using the automesh function of the CAD system [37]. Understanding these variables helps better in the comprehension of mechanical and biomechanical relationships between the socket and residual limb. However, in several cases of modeling, the displacement during donning the socket is neglected [36, 38]. As such, the automatic contact method was applied to overcome these defects [39] to analyze the magnetic resonance imaging (MRI) and skeletal structure using the Mimics software [40].

Software programs, such as SolidWorks (SolidWorks Corporation, MA, USA), Abaqus (Hibbitt, Karlsson \& Sorensen, Inc., Pawtucket, RI, USA), magnetic resonance MRI, and XRY Dynamic, have been widely used to understand the biomechanics of suspension systems and residual limb interfaces. After transferring the model and data from Solidworks to Abaqus, FEM assumes that the bones, fat, and muscles are the same elements and form a monolith with different mechanical properties [41]. For the sake of simplicity, the assumption in FEM is that the knee angle does not change with different loadings [40]. Jia et al. studied external and internal parameter and assumed that no motion relationship exists between the residual limb and socket during locomotion [16].

All techniques used for assessing pressure and socketresidual limb tension were aimed at increasing accuracy and producing results approximated to the practical and medical 
situation. The study on the residual limb-socket interface behavior in a dynamic state has automatically extended the research scope. Some studies have highlighted the mutual effect of the hard and soft tissues of residual limb (e.g., effect of knee movement, changes in the position of residual limb bones, and their function in generating tension and shear forces). The results of these investigations were expected to contribute to practical improvements in socket construction, mainly for the pain management due to socket misfit. Thus, pain perception was evaluated using technical and computerized systems to redesign and rectify the socket prior to actual construction in accordance with the obtained results [42].

3.2. Deep-Tissue Damage. Pressure and weight-induced stress, as well as the reaction force of socket-residual limb, may damage the skin. These factors can also cause severe pain due to compression or tension. Several studies have been conducted on deep-tissue damage (DTD) to understand the major causes of such damage [43]. Portnoy et al. conducted a study through $2 \mathrm{D}$ and $3 \mathrm{D}$ modeling to prepare a preventive model for the DTD in transtibial amputation [44]. Any pressure on the skin affects all internal tissues [43]. The skin has mutual interaction not only with the socket's interface but also with tissues, tibia, fibula, and muscles. The tibia and fibula are parts of the foot and leg set, and all femoral movements and their resultant displacements make it extremely difficult to identify the pressure points in the residual limb $[36,45]$.

The possibility of evaluating and recording data and their exchange in mechanical and biomechanical evaluation systems, such as FEM, is the main index of this socket design model [46]. By contrast, rectification is a challenging aspect of this method. Extensive research on the use of FEM has covered the features of materials used in the socket and liner, geometric dimensions of the socket-residual limb, and forces and their effects on the configuration of the artificial leg, shear stress intensity, pressure distribution, and friction. The capabilities of existing software products were effectively used to obtain a correct visualization of the mutual residual limbsocket relationship.

3.3. Sensing Pressure. Researchers have examined the defects of measuring instruments, weakness of existing sensors in terms of size and sensitivity and impact of heat, which casted doubt on research results. Lee and Zhang aimed to rectify the socket design in a virtual environment before construction through the pain perception threshold as an evaluation criterion [42]. The oral report of the wearer was used as a credible measure for evaluation, rectification, and actual construction of the socket. Additionally, special sensors were utilized to evaluate the pressure between the socket and residual limb and between the liner and socket (Table 2). The most commonly used sensors are fluid-filled transducers, pneumatic transducers, printed circuit sheet sensors, and diaphragm deflection strain-gauge sensors. Modern biofeedback has been used to record the pressure in dynamic and static states. Measurement systems include shear stress neuromuscular system, 3D computer modeling, prototype socket sensor matrices, customized pressure vessels, Rincoe socket fitting system, Tekscan F-Socket pressure measurement system, and novel pliance system. The thickness of these sensors and systems, albeit small, affects the results of studies [47, 48]. The accuracy and response of sensors in curved areas, as well as lumps, have also been compared [48]. The only available system that allows clinical use is smart pyramid called Europa $[11,13,14]$. However, it only provides forces applied below the socket, not the forces or pressure applied inside the prosthetic socket or between the residual limb and liner. Yet, the same technology might be improved to be used inside the socket. The current available pressure mapping systems are complicated and expensive and require laboratory settings. These make it impossible to be used in clinical settings. There is the need to develop portable wireless systems that can be easily used in rehabilitation clinics for objective real-time assessment.

3.4. Socket Design and Pressure Distribution. Poonekar (1992) enumerated several factors considered in producing a socket, such as scientific evaluations, possibility of economic production, actual living conditions of person with disabilities, and disability. He likewise highlighted the new technological capacity for developing and using new techniques and materials for lower limb amputations [49]. The adaptation and fitness of existing instruments for prosthetic requirements facilitate the generation of quantitative data on prosthetics. Several techniques, including computer-aided design (CAD) and computer-aided manufacture (CAM), have been also used to reduce the fabrication time of sockets. Undoubtedly, reducing the fabrication time via the CAD/CAM method directly affects the costs [50]. Accordingly, the time is reduced, but it fails to improve the quality of the prosthesis fit [24]. Fabricating duplicate sockets [50] appears irrational because residual limb changes over time and the socket should be rectified only by an experienced prosthetist. Utmost satisfaction is achieved through rectification by prosthetists. The problem of dimensional changes has traditionally been solved by the addition or elimination equal to the change, such as wearing socks. In fact, dissatisfaction with prostheses is mainly caused by strains and injuries associated with socket fit. Sanders et al. found that such changes are difficult to control, predict, minimize, and compare [51]. Their findings showed the effect of time and changes in pressure distribution in the residual limb and the socket interface, as well as increased risk of injuries in residual limb [33].

The human skin does not have the intrinsic capacity to remain undamaged under prosthetic pressure. Naturally, the skin suffers from external or internal forces and undergoes mechanical changes. These changes exert long-term negative effects (albeit minimal) on the skin, which causes reaction and damage, not only to the skin but also to the area underneath [44]. Sanders et al. obtained results that could be used for modeling, such as the association of increased force inside the socket with increased friction between residual limb and socket [59]. They also tested shear forces and concurrently measured the normal state and shear stress with a specialized converter [60] and reported that shear stress damages the residual limb and weakens the skin structure [59]. 
TABLE 1: Characteristics of subjects in the studied literature.

\begin{tabular}{lccc}
\hline Study $(n=20)$ & Age (year) & Cause of amputation (\%) & Residual limb length (cm) \\
\hline Sanders et al. (1992) [34] & $23-46$ & Trauma & $13.7( \pm 2.0)$ \\
Sanders et al. (1993) [33] & $23-46$ & Trauma & $11-15$ \\
Zhang et al. (1996) [36] 36 Unknown & Unknown \\
Zhang et al. (1998) [45] & Unknown & Trauma & Unknown \\
Sanders et al. (2000) [51] & $43-75$ & Trauma-vascular disease & 14.5 \\
Goh et al. (2003) [52] & $29-81$ & Trauma & Unknown \\
Lin et al. (2004) [37] & $31-62$ & Unknown & Unknown \\
Jia et al. (2004) [16] & Unknown & Unknown & Unknown \\
Lee et al. (2004) [53] & 56 & Trauma & $10.4-20.5$ \\
Sanders et al. (2005) [54] & Unknown & Trauma & Unknown \\
Lee and Zhang (2007) [42] & $28-61$ & Trauma & 12.76 \\
Portnoy et al. (2008) [44] & 55 & Tumor-trauma & Unknown \\
Wolf et al. (2009) [55] & 29 & Trauma-vascular disease & $12-17.7$ \\
Abu Osman et al. (2010) [56] & $43-59$ & Trauma-vascular disease & $10.5-17.5$ \\
Dumbleton et al. (2009) [57] & $34-77$ & Trauma-vascular disease & Unknown \\
Boutwell et al. (2012) [58] & $25-69$ & Trauma-vascular disease & $13-15$ \\
Kobayashi et al. (2012) [13] & $43-67$ & Trauma-vascular disease & $13-15$ \\
Kobayashi et al. (2013) [14] & $18-60$ & Trauma-vascular disease & $13-16$ \\
Boone et al. (2013) [11] & $18-61$ & $18-61$ &
\end{tabular}

Computerized and FEM modeling assessments still do not match clinical and prosthetic evaluations for producing a systematic pattern and a reliable index. Such gap exists despite the use of algorithms to rectify final models [61]. Vicon motion analysis (Oxford Metrics, UK) has been also used to assess force in the dynamic phase. The mutual effect of hard and soft tissues of the residual limb has been either taken as fixed or ignored to simplify the equation or computerized assessment. Among these variables are the impact of knee angle and its effect on pressure between the socket and residual limb during walking [62]. Jia et al. aimed to predict these effects via FEM modeling and improve socket rectification [62]. Volume, weight, and thickness of measuring transducers and necessary simultaneous measurement of normal and shear stress necessitated redesigning of transducers [56].

\section{Discussion}

The systematic investigation of an artificial leg requires quantitative and qualitative data. Various prosthetic components have been investigated in the past. The findings do not completely apply to the clinical settings. Studies have been limited to an increased and improved biomechanical understanding of the interactions among the components of an artificial leg. Quantitative and qualitative studies have not created an accurate and extendable model because of the breadth and plurality of effective parameters in the mutual relationship between the residual limb and the socket [63]. In FEM-based assessments, several modeling parameters are either considered fixed or eliminated based on the preference of the model maker. These assessments approximate reality and identify areas that endure minimum and maximum pressures. Studying a part of the artificial leg and the interaction with the residual limb requires elimination of the effects of other parts. Accordingly, results should be constantly obtained after removing limits and variables. In future studies, the artificial leg should be considered as an integrated system. Moreover, the entire prosthesis should be evaluated in a comprehensive model. It is suggested that new research tools are developed that enable both clinical and laboratory measurements.

All existing studies have been conducted in the context of available sockets. Moreover, a change in performance likely alters existing logic fundamentally. Measuring methods have been applied to the assumption that standard available sockets are used. If new approaches and designs for constructing socket liners are established, then measurement and results would completely change. Application of new technologies requires update and hinges on the expertise of not only prosthetists and physicians but also designers and engineers. In fact, the emergence of new sockets and liners has transformed assessment methods. Prosthetists use these products to solve the problems of patient. Thus, indepth research improves prosthetists' understanding, thereby increasing patient satisfaction. It can be made possible by developing user-friendly systems for pressure measurement that allows prosthetists evaluating the prosthesis based on simple reports before delivery to the patient.

Several studies have generated favorable results with respect to modeling, as well as experimental, technical, and mechanical equations. However, these results are impractical because of the hypotheses that should be eliminated or taken as fixed in computerized modeling. For instance, modeling friction produces unreliable results because several parameters cannot be accommodated by modeling using 


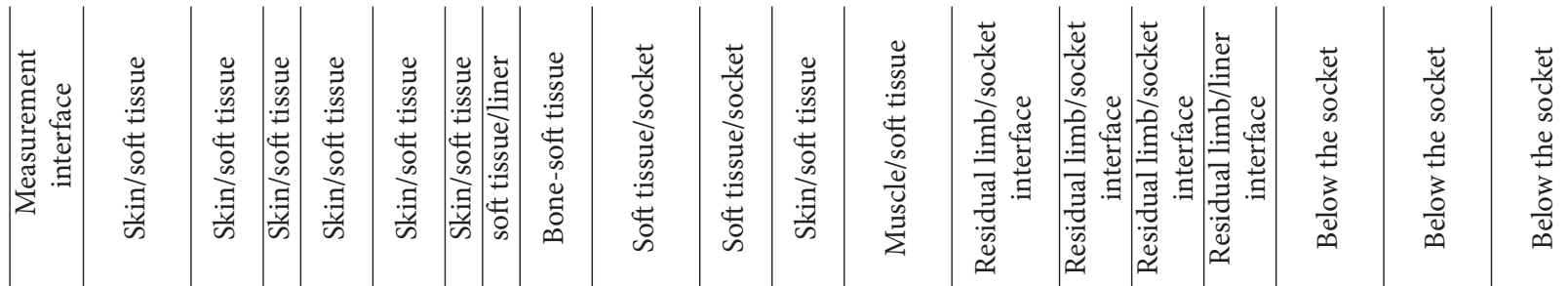

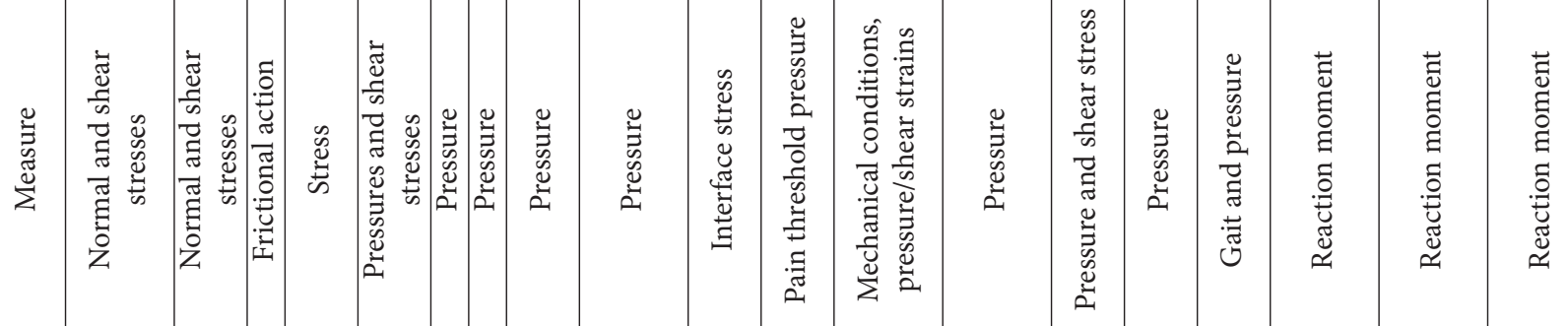

茫

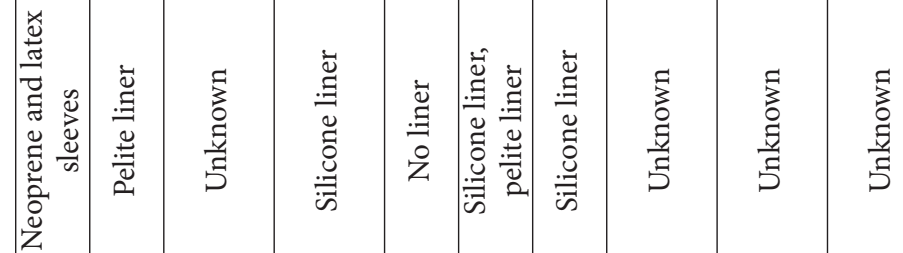

㝏

$\log$

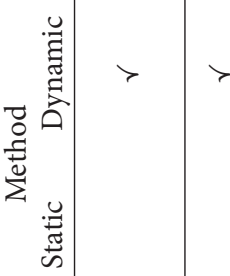

気

蒻 2

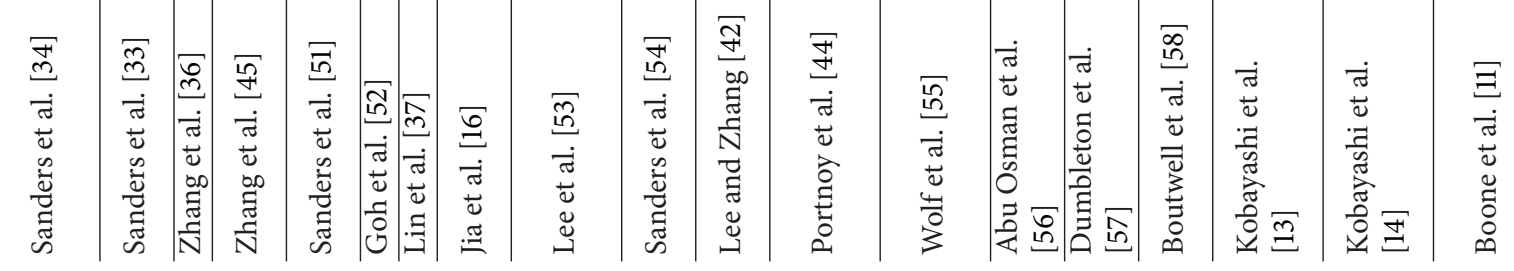


the current software. Therefore, the skin and skin subtissues bear the pressure for the moment. In fact, a trade-off exists between the advantages and possibilities of having an artificial leg. Accordingly, all studies should strive to reduce these disadvantages while increasing the advantages to achieve an optimal final product

The increasing popularity of silicon liners has affected the manner by which future evaluations may be conducted. For instance, these evaluations may focus on skin-silicon relationship, advantages and defects, biomechanical performance evaluation, comparison of different liners based on ten years of studies on residual limb-socket interface, pressure, and shear stress. This requires creation of a new discipline, which is different from prosthetics and focuses on production technology, because measuring and modeling software and instruments are constantly being developed. Psychological factors are also among the most important factors that should be taken into account in investigations and experiments on people with lower limb prosthesis [6]. Satisfaction analysis has yielded interesting results in past and opened a new horizon for discussing effective parameters of wearer satisfaction. The effect of the wearer-prosthetist relationship is a major index of user satisfaction [7]. The final aim of the studies is the satisfaction of people with lower limb prosthesis. It can be concluded from the findings that the best model for satisfaction evaluation is the one that integrates both objective data and subjective feedback of the users. One study revealed that different results are obtained despite the same fabrication process and quality used by specialist prosthetists. Hence, satisfaction becomes an internal and psychological matter.

Future studies are expected to deepen understanding of the relationships among vital factors in the design and fabrication of existing sockets. In addition, researchers need to find new and inexpensive solutions that are competitive, both in terms of performance and condition. Since 1945, numerous studies have measured pressure distribution inside the socket for comparative and biomechanical evaluation and for better understanding the residual limb-socket interface [64]. These studies have improved the understanding of the effective parameters in such relationship. However, all employed methods have been shown to possess accuracy constraints. Nevertheless, these studies have shed light on an extremely important aspect, which is the pressure distribution around the residual limb. This pressure distribution directly and indirectly affects the effective indices of user satisfaction, issues relevant to residual limb interaction, and mechanical and biomechanical variables of the socket. The skin has chemical, physical, and mechanical characteristics, which undergo problematic changes when it interacts with the socket and suspension system (Table 1). These changes cause skin damage. Damage and discomfort occasionally occur in blood vessels and circulation [65]. Evaluation and measurement of these changes and heat around the residual limb, as well as correct understanding of this interaction, are important issues [66].

Experts and engineers have sufficiently focused on prosthetics; however, few databases have been created. Compared with databases in other fields, those relevant to prosthetics and orthotics are extremely few, such as National Amputee Statistical Database, RECAL Information Services [67], National Prosthetics Patient Database [68], REHABDATA, Center for International Rehabilitation Research Information and Exchange, and AbleData. Hence, researchers of prosthetics prefer an interdisciplinary approach because of the direct and indirect relationship of this area with other sciences [69]. Finally, rehabilitation is a teamwork consisting of surgeon, physical therapist, occupational therapist, prosthetist, and psychologist [70]. Hence, proper fit may not be achieved if the prosthetist design the most comfortable and intelligent socket, but the surgery and postoperation physiotherapy are insufficient.

\section{Conclusion}

The complexity of the issue, as well as overlapping of engineering and medical parameters, requires cooperation of industrial designers, engineers, and medical experts in a consistent system. Aesthetic parameters should be also considered in this area as part of evaluation index for patient satisfaction. Researchers have studied pressure and stress measurement, but quantitative evaluations remain inapplicable in clinical settings. The central issue is fitting and biomechanical interactions for fit. In addition to the changes in socket fitness over daily activities, attention should be given to the impact of time on residual limb and parametric changes. The time has come to provide better solution to socket design and suspension system through the expertise of specialists, innovative designs, and new measuring instruments. Prosthetic components, such as the pylon, require redesign. In addition, intelligent materials can completely transform the socket design.

\section{Conflict of Interests}

The authors declare that there is no conflict of interests regarding the publication of this paper.

\section{Acknowledgment}

This study was supported by UM/MOHE/HIR Project no. D000014-16001.

\section{References}

[1] T. R. Dillingham, L. E. Pezzin, and E. J. MacKenzie, "Limb amputation and limb deficiency: epidemiology and recent trends in the United States," Southern Medical Journal, vol. 95, no. 8, pp. 875-883, 2002.

[2] D. Bader, C. Bouten, D. Colin, and C. W. J. Oomens, Pressure Ulcer Research, Current and Future Perspectives, Springer, Berlin, Germany, 2010.

[3] L. B. Ebskov, "Level of lower limb amputation in relation to etiology: an epidemiological study," Prosthetics and Orthotics International, vol. 16, no. 3, pp. 163-167, 1992.

[4] Information Services Division of NHS Scotland, The Amputee Statistical Database for the United Kingdom. National Amputee Statistical Database (NASDAB), 2004-2005. 
[5] A. I. Adler, E. J. Boyko, J. H. Ahroni, and D. G. Smith, "Lowerextremity amputation in diabetes: the independent effects of peripheral vascular disease, sensory neuropathy, and foot ulcers," Diabetes Care, vol. 22, no. 7, pp. 1029-1035, 1999.

[6] O. Horgan and M. MacLachlan, "Psychosocial adjustment to lower-limb amputation: a review," Disability and Rehabilitation, vol. 26, no. 14-15, pp. 837-850, 2004.

[7] T. R. Dillingham, L. E. Pezzin, E. J. MacKenzie, and A. R. Burgess, "Use and satisfaction with prosthetic devices among persons with trauma-related amputations: a long-term outcome study," The American Journal of Physical Medicine and Rehabilitation, vol. 80, no. 8, pp. 563-571, 2001.

[8] S. Ali, N. A. Abu Osman, M. M. Naqshbandi, A. Eshraghi, M. Kamyab, and H. Gholizadeh, "Qualitative study of prosthetic suspension systems on transtibial amputees' satisfaction and perceived problems with their prosthetic devices," Archives of Physical Medicine and Rehabilitation, vol. 93, no. 11, pp. 19191923, 2012.

[9] R. Fitzpatrick, "Surveys of patient satisfaction: I-important general considerations," The British Medical Journal, vol. 302, no. 6781, pp. 887-889, 1991.

[10] A. Chow, E. K. Mayer, A. W. Darzi, and T. Athanasiou, "Patient-reported outcome measures: the importance of patient satisfaction in surgery," Surgery, vol. 146, no. 3, pp. 435-443, 2009.

[11] D. A. Boone, T. Kobayashi, T. G. Chou et al., "Influence of malalignment on socket reaction moments during gait in amputees with transtibial prostheses," Gait and Posture, vol. 37, no. 4, pp. 620-626, 2013.

[12] T. Kobayashi, M. S. Orendurff, A. K. Arabian, T. G. RosenbaumChou, and D. A. Boone, "Effect of prosthetic alignment changes on socket reaction moment impulse during walking in transtibial amputees," Journal of Biomechanics, vol. 47, pp. 1315-1323, 2014.

[13] T. Kobayashi, M. S. Orendurff, M. Zhang, and D. A. Boone, "Effect of transtibial prosthesis alignment changes on out-ofplane socket reaction moments during walking in amputees," Journal of Biomechanics, vol. 45, no. 15, pp. 2603-2609, 2012.

[14] T. Kobayashi, M. S. Orendurff, M. Zhang, and D. A. Boone, "Effect of alignment changes on sagittal and coronal socket reaction moment interactions in transtibial prostheses," Journal of Biomechanics, vol. 46, no. 7, pp. 1343-1350, 2013.

[15] S. Gabbiadini, Knowledge-Based Design of Lower Limb Prosthesis, Department of Mechanical and Management Innovation University of Padua, 2011.

[16] X. Jia, M. Zhang, and W. C. C. Lee, "Load transfer mechanics between trans-tibial prosthetic socket and residual limbdynamic effects," Journal of Biomechanics, vol. 37, no. 9, pp. 13711377, 2004.

[17] L. E. Pezzin, T. R. Dillingham, E. J. MacKenzie, P. Ephraim, and P. Rossbach, "Use and satisfaction with prosthetic limb devices and related services," Archives of Physical Medicine and Rehabilitation, vol. 85, no. 5, pp. 723-729, 2004.

[18] C. W. Radcliffe and J. Foort, The Patellar Tendon Bearing below Knee Prosthesis, University of California, Berkeley, Calif, USA, 1961.

[19] J. Galdik, "Th e below-knee suction socket," Orthopedic and Prosthetic Appliance Journal, vol. 9, p. 4, 1955.

[20] C. B. Taft, "The patellar-tendon-supracondylar (PTS) prosthesis: report Of A preliminary study," Inter-Clinic Information Bulletin, vol. 7, pp. 16-22, 1968.
[21] O. Kristinsson, "The ICEROSS concept: a discussion of a philosophy," Prosthetics and Orthotics International, vol. 17, no. 1, pp. 49-55, 1993.

[22] C. E. Fillauer, C. H. Pritham, and K. D. Fillauer, "Evolution and development of the silicone suction socket (3S) for below-knee prostheses," Journal of Prosthetics and Orthotics, vol. 1, no. 2, pp. 92-103, 1989.

[23] J. W. Steege, D. S. Schnur, and D. S. Childress, "Prediction of pressure in the below-knee socket interface by finite element analysis," in Proceedings of the ASME Symposium on the Biomechanics of Normal and Pathological Gait, 1987.

[24] P. Sewell, S. Noroozi, J. Vinney, R. Amali, and S. Andrews, "Static and dynamic pressure prediction for prosthetic socket fitting assessment utilising an inverse problem approach," Artificial Intelligence in Medicine, vol. 54, no. 1, pp. 29-41, 2012.

[25] M. W. Legro, G. D. Reiber, D. G. Smith, M. del Aguila, J. Larsen, and D. Boone, "Prosthesis evaluation questionnaire for persons with lower limb amputations: assessing prosthesis-related quality of life," Archives of Physical Medicine and Rehabilitation, vol. 79, no. 8, pp. 931-938, 1998.

[26] M. C. Grise, C. Gauthier-Gagnon, and G. G. Martineau, "Prosthetic profile of people with lower extremity amputation: conception and design of a follow-up questionnaire," Archives of Physical Medicine and Rehabilitation, vol. 74, no. 8, pp. 862-870, 1993.

[27] G. Ferriero, D. Dughi, D. Orlandini, T. Moscato, D. Nicita, and F. Franchignoni, "Measuring long-term outcome in people with lower limb amputation: cross-validation of the Italian versions of the Prosthetic Profile of the Amputee and Prosthesis Evaluation Questionnaire," Europa Medicophysica, vol. 41, no. 1, pp. 1-6, 2005.

[28] D. A. Boone and K. L. Coleman, "Use of the prosthesis evaluation questionnaire (PEQ)," Journal of Prosthetics and Orthotics, vol. 18, no. 6, pp. 68-79, 2006.

[29] L. Kark and A. Simmons, "Patient satisfaction following lowerlimb amputation: the role of gait deviation," Prosthetics and Orthotics International, vol. 35, no. 2, pp. 225-233, 2011.

[30] K. L. Coleman, D. A. Boone, L. S. Laing, D. E. Mathews, and D. G. Smith, "Quantification of prosthetic outcomes: elastomeric gel liner with locking pin suspension versus polyethylene foam liner with neoprene sleeve suspension," Journal of Rehabilitation Research and Development, vol. 41, no. 4, pp. 591-602, 2004.

[31] F. B. van de Weg and D. A. W. M. van der Windt, "A questionnaire survey of the effect of different interface types on patient satisfaction and perceived problems among trans-tibial amputees," Prosthetics and Orthotics International, vol. 29, no. 3, pp. 231-239, 2005.

[32] S. Laing, P. V. Lee, and J. C. Goh, "Engineering a trans-tibial prosthetic socket for the lower limb amputee," Annals of the Academy of Medicine Singapore, vol. 40, no. 5, pp. 252-259, 2011.

[33] J. E. Sanders, C. H. Daly, and E. M. Burgess, "Clinical measurement of normal and shear stresses on a trans-tibial stump: characteristics of wave-form shapes during walking," Prosthetics and Orthotics International, vol. 17, no. 1, pp. 38-48, 1993.

[34] J. E. Sanders, C. H. Daly, and E. M. Burgess, "Interface shear stresses during ambulation with a below-knee prosthetic limb," Journal of Rehabilitation Research and Development, vol. 29, no. 4, pp. 1-8, 1992.

[35] D. Tsiokos, G. T. Kanellos, G. Papaioannou, and S. Pissadakis, "Fiber Optic-Based Pressure Sensing Surface for Skin Health Management in Prosthetic and Rehabilitation Interventions," 2012. 
[36] M. Zhang, A. R. Turner-Smith, V. C. Roberts, and A. Tanner, "Frictional action at lower limb/prosthetic socket interface," Medical Engineering \& Physics, vol. 18, no. 3, pp. 207-214, 1996.

[37] C. Lin, C. Chang, C. Wu, K. Chung, and I. Liao, "Effects of liner stiffness for trans-tibial prosthesis: a finite element contact model," Medical Engineering and Physics, vol. 26, no. 1, pp. 1-9, 2004.

[38] M. Zhang, M. Lord, A. R. Turner-Smith, and V. C. Roberts, "Development of a non-linear finite element modelling of the below-knee prosthetic socket interface," Medical Engineering and Physics, vol. 17, no. 8, pp. 559-566, 1995.

[39] S. G. Zachariah and J. E. Sanders, "Finite element estimates of interface stress in the trans-tibial prosthesis using gap elements are different from those using automated contact," Journal of Biomechanics, vol. 33, no. 7, pp. 895-899, 2000.

[40] W. C. C. Lee, M. Zhang, D. A. Boone, and B. Contoyannis, "Finite-element analysis to determine effect of monolimb flexibility on structural strength and interaction between residual limb and prosthetic socket," Journal of Rehabilitation Research \& Development, vol. 41, no. 6, pp. 775-786, 2004.

[41] S. Portnoy, I. Siev-Ner, N. Shabshin, A. Kristal, Z. Yizhar, and A. Gefen, "Patient-specific analyses of deep tissue loads post transtibial amputation in residual limbs of multiple prosthetic users," Journal of Biomechanics, vol. 42, no. 16, pp. 2686-2693, 2009.

[42] W. C. C. Lee and M. Zhang, "Using computational simulation to aid in the prediction of socket fit: a preliminary study," Medical Engineering and Physics, vol. 29, no. 8, pp. 923-929, 2007.

[43] A. Stekelenburg, D. Gawlitta, D. L. Bader, and C. W. Oomens, "Deep tissue injury: how deep is our understanding?" Archives of Physical Medicine and Rehabilitation, vol. 89, no. 7, pp. 14101413, 2008.

[44] S. Portnoy, Z. Yizhar, N. Shabshin et al., "Internal mechanical conditions in the soft tissues of a residual limb of a trans-tibial amputee," Journal of Biomechanics, vol. 41, no. 9, pp. 1897-1909, 2008.

[45] M. Zhang, A. R. Turner-Smith, A. Tanner, and V. C. Roberts, "Clinical investigation of the pressure and shear stress on the trans- tibial stump with a prosthesis," Medical Engineering o Physics, vol. 20, no. 3, pp. 188-198, 1998.

[46] B. Roith, A. Troll, and F. Rieg, "Integrated finite element analysis (FEA) in three-dimensional computer aided design programs (CAD)-overview and comparison," in Proceedings of the 16th International Conference on Engineering Design (ICED '07), Paris, France, July 2007.

[47] A. W. P. Buis and P. Convery, "Calibration problems encountered while monitoring stump/socket interface pressures with force sensing resistors: techniques adopted to minimise inaccuracies," Prosthetics \& Orthotics International, vol. 21, no. 3, pp. 179-182, 1997.

[48] A. A. Polliack, R. C. Sieh, D. D. Craig, S. Landsberger, D. R. McNeil, and E. Ayyappa, "Scientific validation of two commercial pressure sensor systems for prosthetic socket fit," Prosthetics and Orthotics International, vol. 24, no. 1, pp. 63-73, 2000.

[49] P. Poonekar, "Prosthetics and orthotics in India," in Prosthetic and Orthotic Research for the Twenty-First Century, National Institute of Child Health and Human Development, Bethsheda, Md, USA, 1992.

[50] A. L. Steele, "A survey of clinical CAD/CAM use," Journal of Prosthetics and Orthotics, vol. 6, pp. 42-47, 1994.
[51] J. E. Sanders, J. M. Greve, C. Clinton, and B. J. Hafner, “Changes in interface pressure and stump shape over time: preliminary results from a trans-tibial amputee subject," Prosthetics and Orthotics International, vol. 24, no. 2, pp. 163-168, 2000.

[52] J. C. H. Goh, P. V. S. Lee, and S. Y. Chong, "Stump/socket pressure profiles of the pressure cast prosthetic socket," Clinical Biomechanics, vol. 18, no. 3, pp. 237-243, 2003.

[53] W. C. C. Lee, M. Zhang, D. A. Boone, and B. Contoyannis, "Finite-element analysis to determine effect of monolimb flexibility on structural strength and interaction between residual limb and prosthetic socket," Journal of Rehabilitation Research and Development, vol. 41, no. 6, pp. 775-786, 2004.

[54] J. E. Sanders, S. G. Zachariah, A. K. Jacobsen, and J. R. Fergason, "Changes in interface pressures and shear stresses over time on trans-tibial amputee subjects ambulating with prosthetic limbs: comparison of diurnal and six-month differences," Journal of Biomechanics, vol. 38, no. 8, pp. 1566-1573, 2005.

[55] S. I. Wolf, M. Alimusaj, L. Fradet, J. Siegel, and F. Braatz, "Pressure characteristics at the stump/socket interface in transtibial amputees using an adaptive prosthetic foot," Clinical Biomechanics, vol. 24, no. 10, pp. 860-865, 2009.

[56] N. A. Abu Osman, W. D. Spence, S. E. Solomonidis, J. P. Paul, and A. M. Weir, "Transducers for the determination of the pressure and shear stress distribution at the stump-socket interface of trans-tibial amputees," Proceedings of the Institution of Mechanical Engineers B: Journal of Engineering Manufacture, vol. 224, no. 8, pp. 1239-1250, 2010.

[57] T. Dumbleton, A. W. P. Buis, A. McFadyen et al., "Dynamic interface pressure distributions of two transtibial prosthetic socket concepts," Journal of Rehabilitation Research and Development, vol. 46, no. 3, pp. 405-415, 2009.

[58] E. Boutwell, R. Stine, A. Hansen, K. Tucker, and S. Gard, "Effect of prosthetic gel liner thickness on gait biomechanics and pressure distribution within the transtibial socket," Journal of Rehabilitation Research and Development, vol. 49, no. 2, pp. 227-240, 2012.

[59] J. E. Sanders, J. R. Fergason, S. G. Zachariah, and A. K. Jacobsen, "Interface pressure and shear stress changes with amputee weight loss: case studies from two trans-tibial amputee subjects," Prosthetics \& Orthotics International, vol. 26, no. 3, pp. 243-250, 2002.

[60] J. E. Sanders, S. B. Mitchell, S. G. Zachariah, and K. Wu, "A digitizer with exceptional accuracy for use in prosthetics research: a technical note," Journal of Rehabilitation Research and Development, vol. 40, no. 2, pp. 191-195, 2003.

[61] M. Dewar, P. Jarman, D. Reynolds, H. Crawford, J. MacCoughlan, and A. Crew, "Computer aided socket design (CASD): UCL system based on full shape sensing," Bioengineering Centre Report, University College London, London, UK, 1985.

[62] X. H. Jia, M. Zhang, X. B. Li, and W. C. C. Lee, "A quasi-dynamic nonlinear finite element model to investigate prosthetic interface stresses during walking for trans-tibial amputees," Clinical Biomechanics, vol. 20, no. 6, pp. 630-635, 2005.

[63] Q. Ling, "Biomechanics-a multidisciplinary discipline subject," Journal of Medical Biomechanics, vol. 23, no. 2, pp. 97-98, 2008.

[64] E. Vasconcelos, Modern Methods of Amputation, Philosophical Library, New York, NY, USA, 1945.

[65] K. Hagberg and R. Brånemark, "Consequences of non-vascular trans-femoral amputation: a survey of quality of life, prosthetic use and problems," Prosthetics and Orthotics International, vol. 25, no. 3, pp. 186-194, 2001. 
[66] J. T. Peery, W. R. Ledoux, and G. K. Klute, "Residual-limb skin temperature in transtibial sockets," Journal of Rehabilitation Research and Development, vol. 42, no. 2, pp. 147-154, 2005.

[67] RECAL, "Search the world's most comprehensive database in the field of prosthetics, orthotics," 2007.

[68] NPPD, National Prosthetics Patient Database (NPPD), 2013.

[69] C. C. Nielsen, "A survey of amputees: functional level and life satisfaction, information needs and the prosthetist's role," Journal of Prosthetics and Orthotics, vol. 3, no. 3, pp. 125-129, 1990.

[70] L. Andrews, L. Anderson, S. Fairbain, and L. Downing, "Care planning for children with lower limb amputation.," Nursing children and young people, vol. 24, no. 1, pp. 14-19, 2012. 


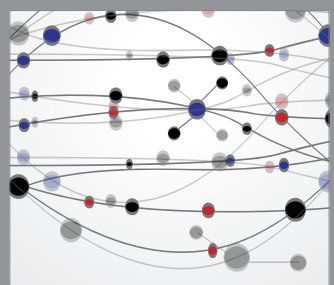

The Scientific World Journal
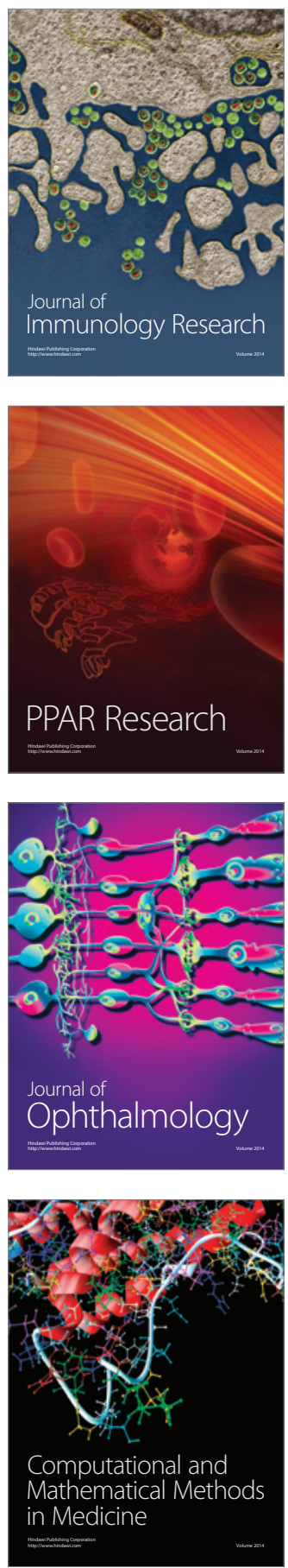

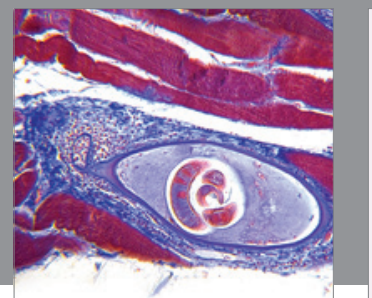

Gastroenterology

Research and Practice
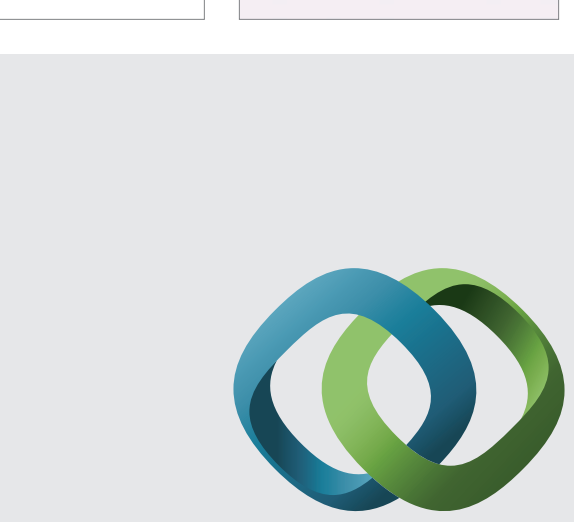

\section{Hindawi}

Submit your manuscripts at

http://www.hindawi.com
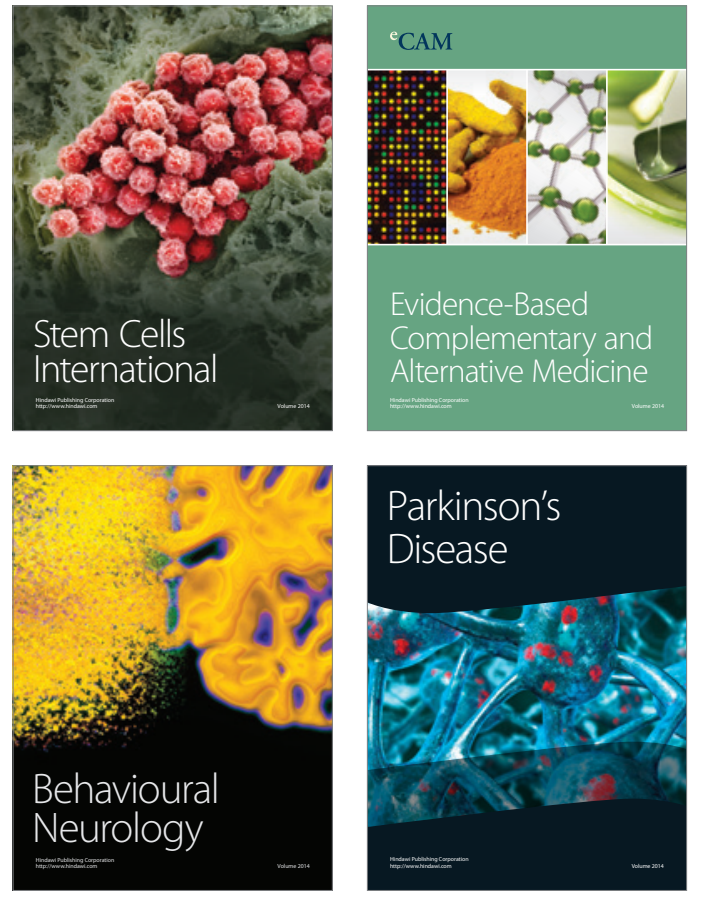
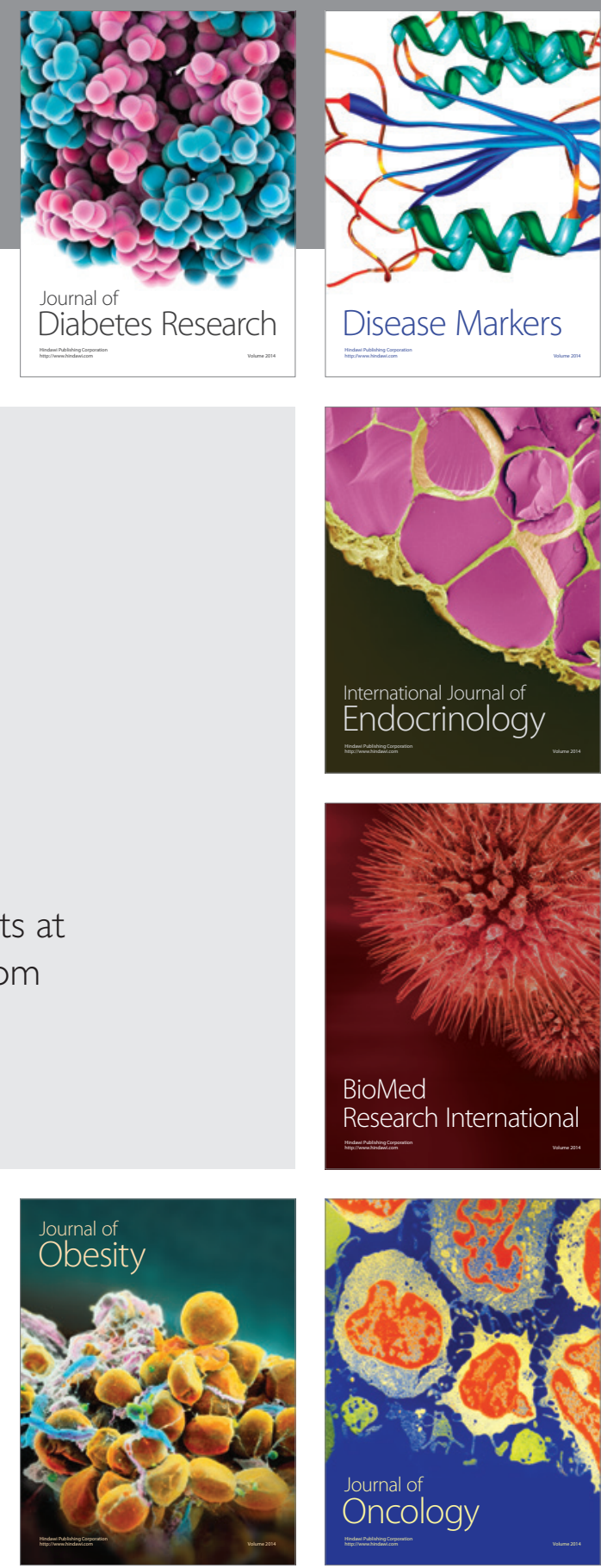

Disease Markers
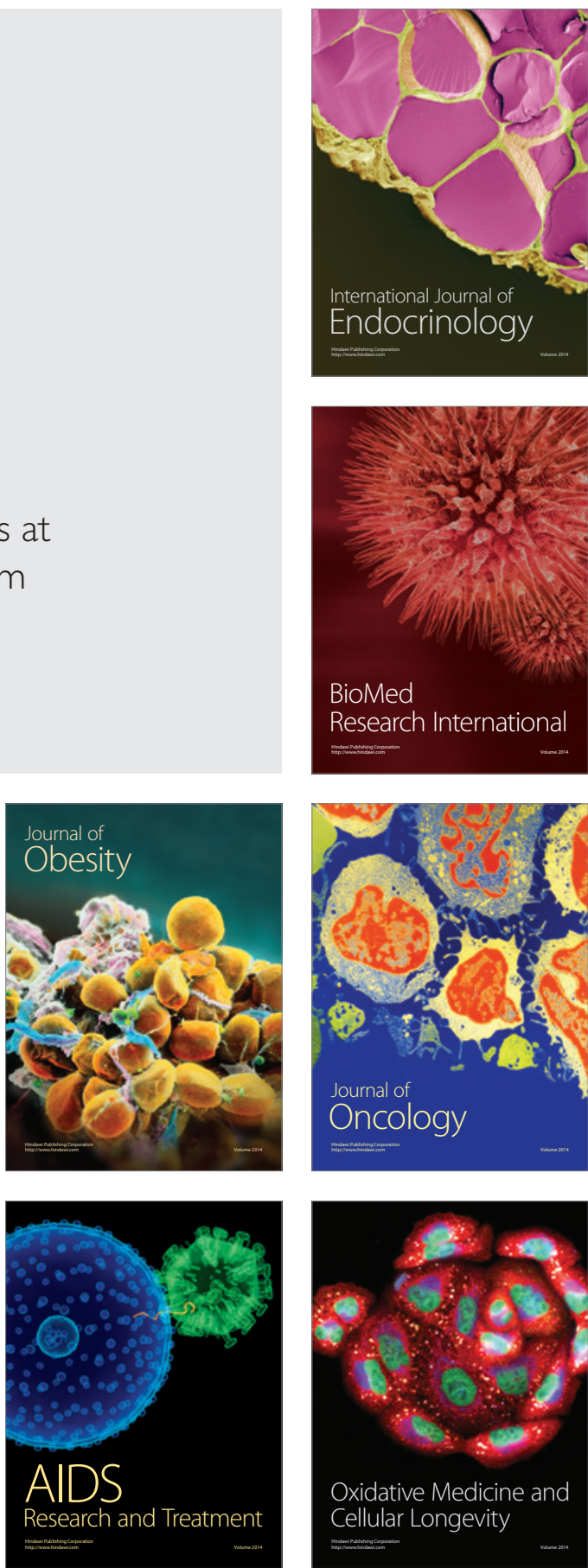